\title{
Ética militar en la contrainsurgencia: las operaciones militares en el marco de un conflicto armado interno ${ }^{1}$
}

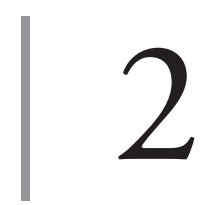

https://doi.org/10.21830/9789585377134.02

\author{
Carlos Alberto Ardila Castro ${ }^{2}$ \\ Henry Mauricio Acosta Guzmán ${ }^{3}$ \\ Roger Jiménez Reina ${ }^{4}$ \\ Javier Alonso Giraldo Ramirez" \\ Escuela Superior de Guerra "General Rafael Reyes Prieto"
}

1 Este capítulo presenta los resultados colaborativos de dos proyectos de investigación: (1) "Ética militar en entornos complejos de seguridad y defensa: lecturas y aportes desde la experiencia de las Fuerzas Militares de Colombia”, del grupo de investigación Masa Crítica, de la Escuela Superior de Guerra "General Rafael Reyes Prieto", Colombia, categorizado en B por Minciencias y con código de registro COL0123247, y (2) "Mujeres de arma, seguridad y defensa nacional. Un análisis desde sus percepciones", del grupo de investigación en Ciencias Militares, de la Escuela Militar de Cadetes "General José María Córdova”, Colombia, categorizado en B por Minciencias y con código de registro COL0082556. Los puntos de vista pertenecen a los autores y no reflejan necesariamente los de las instituciones participantes.

$2 \mathrm{PhD}(\mathrm{c})$ en Educación de la Universidad Internacional Iberoamericana, México. Magíster en Negocios y Relaciones Internacionales de la Universidad Militar Nueva Granada. Profesional en Ciencias Militares de la Escuela Militar de Cadetes "General José María Córdova". Profesional en Gerencia de Seguridad y Análisis Sociopolítico de la Escuela de Inteligencia y Contrainteligencia. Docente asociado de la Escuela Superior de Guerra "General Rafael Reyes Prieto", Colombia. Investigador asociado reconocido por Minciencias. Asesor estratégico de la Vicedirección de Investigación y líder del grupo de investigación Centro de Gravedad, de la Escuela Superior de Guerra "General Rafael Reyes Prieto", Colombia. OrCid: https://orcid.org/0000-0002-8774-6176 - Contacto: carlos.ardila@esdegue.edu.co

3 Magíster en Seguridad y Defensa Nacionales de la Escuela Superior de Guerra "General Rafael Reyes Prieto". Estudiante de la Maestría en Derechos Humanos y Derecho Internacional de los Conflictos Armados de la Escuela Superior de Guerra "General Rafael Reyes Prieto". Politólogo de la Universidad Nacional de Colombia. Editor asistente de la Revista Estudios en Seguridad y Defensa e investigador del grupo de investigación Masa Crítica, de la Escuela Superior de Guerra "General Rafael Reyes Prieto", Colombia. OrCID: https://orcid.org/0000-0003-4485-8845 - Contacto:_henry.acosta@esdegue.edu.co

4 Profesional en Política y Relaciones Internacionales de la Universidad Sergio Arboleda. Estudiante de Derecho de la Universidad Sergio Arboleda. Asistente de investigación del semillero de la Escuela Mayor de Derecho de la Universidad Sergio Arboleda, Colombia. OrcID: https://orcid.org/00000001-9658-0051 - Contacto: roger.jimenez@correo.usa.edu.co

5 Coronel del Ejército Nacional de Colombia. Magíster en Inteligencia Estratégica de la Escuela de Inteligencia y Contrainteligencia. Profesional en Ciencias Militares de la Escuela Militar de Cadetes "General José María Córdova”. OrciD: https://orcid.org/0000-0003-1172-1308 - Contacto: javier.giraldo@ buzonejercito.mil.co 


\section{Resumen}

El objetivo de este capítulo de libro es identificar los retos éticos a los que se enfrentan las Fuerzas Armadas en un escenario de guerra asimétrica y guerra híbrida en el marco de un escenario de conflicto armado interno. Se trata de una investigación de carácter cualitativo que recopiló, sistematizó y analizó información de bases de datos académicas e informes gubernamentales para establecer los principales retos éticos. Como resultado de la investigación se observa que, para el marco de un conflicto armado no internacional como el colombiano, las Fuerzas Armadas han ajustado su actuación profesional conforme al respeto de principios internacionales, relacionados con los Derechos Humanos y el Derecho Internacional Humanitario, y a la naturaleza asimétrica e irregular de los actores inmersos en las hostilidades (guerrillas, autodefensas y grupos armados organizados [GAO]). La principal conclusión es que la ética militar es un componente importante en el desarrollo de operaciones militares, pues establece un marco de actuación fundamentado en su doctrina, principios y valores institucionales.

Palabras clave: Derecho Internacional Humanitario; ética; Fuerzas Armadas.

\section{Introducción}

A partir de la conformación de grupos armados irregulares en Colombia durante la década de 1960 se intensificaron las hostilidades contra el Estado y su población civil, que, hasta la fecha, han alcanzado un alto índice de violencia en los territorios rurales en donde existe la presencia permanente de los grupos armados organizados (GAO) y las organizaciones ilegales que operan en función de mantener un poder armado ilegal en territorios donde se desarrollan actividades ilícitas.

En razón a la desmovilización de las Fuerzas Armadas Revolucionarias de Colombia (FARC) en el 2016, se propició una intensificación de la violencia armada contra la población civil, dada la necesidad de los grupos armados ilegales y Grupos Delincuenciales Organizados (GDo) por ocupar espacios, 
controlar los negocios ilícitos y, de esta manera, lograr una financiación permanente de sus operaciones contra el Estado (Jiménez \& Acosta, 2018), siempre empleando la coerción contra la población civil sin importar los alcances.

El punto central de este capítulo gira en torno a la naturaleza y las dinámicas de la guerra interna en Colombia, un conflicto armado de carácter insurgente iniciado por guerrillas de izquierda que han empleado la guerra de guerrillas (Kalyvas, 2009) y la combinación de todas las formas de lucha (Trejos, 2013) para conseguir sus objetivos políticos. No obstante, con la aparición de otros actores armados, como las autodefensas y los carteles del narcotráfico, se intensificó la guerra y los métodos de lucha durante las décadas de 1980 y 1990, desconociendo los principios internacionales relacionados con el respeto de los Derechos Humanos. A pesar de ello, las Fuerzas Armadas, llamadas también Fuerzas Militares (Ejército Nacional, Armada Nacional y Fuerza Aérea), se han mantenido en el respeto de los Derechos Humanos y en la aplicación de los principios de la guerra, una tradición militar expresada en su doctrina, principios y valores que las han destacado internacionalmente por su profesionalismo militar, siendo su ética el principal marco de actuación.

La guerra y la violencia en Colombia han generado dinámicas que van en contra de la moral y la ética, y que se materializan en métodos irregulares y prácticas subversivas que se encuentran fuera del marco jurídico establecido internacionalmente, ya que no dignifican a los combatientes, la población civil ni las víctimas en el desarrollo de las hostilidades (Gil et al., 2019). En consecuencia, con el fin de desestabilizar los territorios, los métodos se han fundamentado en el miedo, la violencia y la deshumanización de las personas, y siguen siendo instrumentos simbólicos de poder empleados por los GAO y GDo contra la población civil y los miembros de la Fuerza Pública (militares y policías).

\section{Metodología}

Esta investigación se desarrolló en tres fases: (1) recopilación bibliográfica conforme a las categorías de análisis; (2) análisis teórico y conceptual en función de los objetivos de la investigación, y (3) construcción del documento. 
La pregunta que guía la investigación es la siguiente: ¿Cuáles son los dilemas éticos en el desarrollo de las operaciones militares en el escenario de un conflicto armado interno? Para responderla se establecieron categorías de análisis tales como: ética militar, operaciones militares y conflicto armado interno. En síntesis, la investigación es cualitativa debido a que hace énfasis en el análisis subjetivo del problema de investigación y su descripción.

\section{La guerra asimétrica y guerra híbrida en el marco de un escenario de conflicto armado interno}

Si se busca describir el fenómeno de la guerra asimétrica y la guerra híbrida en Colombia, debemos tener en cuenta tres características de los fines, los medios y los modos de los actores que han utilizado estas formas de guerra contra el Estado colombiano. La característica inicial es la necesidad de justificar un discurso que valide la idea de la existencia de dichos grupos. La segunda característica es el uso generalizado de la violencia como herramienta para consolidar su discurso y, por último, la tercera, la gran capacidad de estos grupos para adaptarse a las situaciones internas y del sistema internacional, $\mathrm{y}$ con esto alcanzar su fin mediante la combinación de todas las formas de lucha.

Se puede afirmar que el centro de gravedad de un grupo humano que intente confrontar el poder de una autoridad tiene un trasfondo identitario sustentado en lo que estos perciben como la justa causa de su reclamo, lo cual lleva a que la razón de sus motivaciones de lucha sea aceptada por otros, o por lo menos, a conseguir la aceptación popular de la gran mayoría de la población; con esto logran legitimar sus intenciones, por más violentas que sean. No es extraño evidenciar que en los inicios de los conflictos bélicos y a lo largo de la historia, lo que se llama justa causa ha sido una de las mayores preocupaciones de sus implicados, ya que la legitimidad es garantía de respaldo tanto en el interior como en el exterior del conflicto.

Para Wu (1992), describiendo las enseñanzas de Sun Tzu sobre la guerra, es un asunto mental y no de fuerzas, en donde se confrontan dos ideas que describen los intereses particulares de los actores y, finalmente, gana quien tenga mayor capacidad mental de imponer al otro sus ideas. Esto se ve refle- 
jado en la Escuela Estratégica Oriental, donde se privilegia la estrategia que gana batallas sin librarlas físicamente, con lo cual se logra una superioridad moral que paraliza al adversario.

Con la llegada de la modernidad, encontramos un ejemplo de dicha estrategia en la guerra política desarrollada en China en la década de 1930. En esta estrategia encontramos como eje fundamental la guerra ideológica, que según Sheng (1974) tiene como objetivos principales, primero, lograr un sistema ideológico que valide la causa, con lo cual se legitima el discurso y las intenciones, $y$, segundo, atacar el sistema ideológico del adversario para invalidar las ideas que fundan sus aspiraciones de poder y, con ello, no justificar las acciones del enemigo mediante el rechazo popular y negando ese espacio vital para su existencia, el cual es el apoyo de la población. Desde esta perspectiva, los grupos insurgentes colombianos han procurado derrotar al enemigo de clases e instaurar un régimen, que, según ellos, traiga prosperidad a la sociedad (Sarmiento, 2017).

En el caso colombiano, los grupos guerrilleros han construido un elaborado discurso en donde se representan como reformadores sociales, tomando lo que expresó Ernesto el Che Guevara, en su experiencia tras la Revolución Cubana (1959), sobre la cual expresó lo siguiente:

El guerrillero, como reformador social, no solo debe construir un ejemplo en cuanto a su vida, sino que también debe orientar constantemente los problemas ideológicos, con lo que sabe o con lo que pretender hacer en determinado momento y, además, con lo que va aprendiendo en el transcurso de los meses o años de guerra que actúan favorablemente sobre la concepción revolucionaria. (Guevara, 2006, p. 53)

Los grupos irregulares reconocen que su forma de lucha guerrillera obedece de igual forma a otro principio ideológico: la conexión entre la guerra y la política. Según Medina (2013), la guerra irregular que se identifica como guerra revolucionaria ha demandado un cambio disruptivo del sistema actual buscando que toda acción político-organizativa y toda acción militar estén sustentadas en principios políticos ideológicos que las validen. Uno de los ejemplos principales es la estrategia de Trabajo Político Organizativo desarrollada por el Ejército de Liberación Nacional (ELN), la cual busca darle legiti- 
midad política a su discurso, y luego de ello organizar a los grupos humanos donde delinquen para darles validez a sus ideas.

Uno de los mayores retos de los Estados es deslegitimar los constructos ideológicos con los que los grupos insurgentes validan sus fines políticos. Esto se logra construyendo una narrativa que fortalezca los objetivos del Estado. Según Boot (2013), en un conflicto irregular lo más importante es construir la verdad, porque quien la construye gana la guerra sin librar batallas. En el espacio de construcción de verdad se deben utilizar todos los medios y los modos disponibles para generar una convergencia estatal y lograr neutralizar el discurso hegemónico de las insurgencias.

De acuerdo con Mark (2006), el caso colombiano arroja buenas prácticas en este campo, pues se construyó una estrategia sustentable que inició en el gobierno del expresidente Andrés Pastrana (1998-2002) y finalizó en el gobierno del expresidente Juan Manuel Santos (2010-2018) con la firma de los acuerdos de paz con las FARC-EP.

Tomando como segunda característica de la guerra asimétrica y la guerra híbrida que se ha desarrollado en Colombia la capacidad que tienen los actores irregulares de utilizar la violencia generalizada para validar su discurso, se puede evidenciar que dichos grupos han incorporado dentro de sus planes estratégicos y sus actividades operacionales y tácticas la afectación no solamente a la infraestructura estatal, sino también la de todos los sectores de la sociedad.

En el caso específico de las FARC-Ep y tomando nuevamente la reflexión de la conexión de la guerra y la política, se identifica lo siguiente:

Los grupos armados que disputan el poder político a través del ejercicio de la violencia conciben la política no solo desde el campo de la construcción colectiva de acuerdos y la búsqueda consensuada del bienestar general, sino también desde la visión de dominación articulada a la exclusión económica y social de las mayorías por minorías hegemónicas. [...]. En el caso de los guerrilleros, es el más cercano a estas observaciones, el guerrillero se estima a sí mismo como un partisano, su acción armada es una acción política que despliega contra los dominadores. (Medina, 2013, p. 25)

En el desarrollo de su estrategia de validación de su discurso, la insurgencia de las FARC-Ep, y en general todos los grupos insurgentes en Colombia, 
ha conseguido hacer sentir a sus víctimas como culpables de los sistemáticos abusos que han cometido contra ellos. Esta estrategia se enmarca dentro de la guerra psicológica, por intermedio de la cual se busca a través del miedo paralizar al adversario. Según Sheng (1974), dentro de los objetivos de este tipo de guerra se busca la autovalidación y la destrucción del enemigo. En el caso colombiano, se busca la reconstrucción psicológica, con el fin de controlar los sentimientos sobre el Estado y la sociedad, crear resentimiento contra las entidades estatales y, específicamente, contra las Fuerzas Militares, convirtiéndolas en el aparato de represión estatal.

Buscando potenciar su estrategia de validar sus crímenes contra la sociedad colombiana, los grupos insurgentes han desarrollado un muy elaborado trabajo de construcción de verdad o posverdad. La transformación del discurso y la contraposición de verdades tiene el fin de consolidar espacios favorables para su actividad política de cara a los acuerdos que firmaron con el Estado colombiano (Centro Nacional de Memoria Histórica, 2014). En este sentido, los grupos insurgentes, utilizando tanto medios internos como externos, han logrado posicionarse en algunos sectores de la sociedad nacional para respaldar su accionar bajo la legitimidad justa de su causa, y afirmando que esta estuvo orientada a neutralizar los abusos que el Estado realizaba contra la sociedad. En este sentido, han logrado influir en algunos sectores académicos y educativos con el propósito de masificar sus ideas y engañar sobre todo a sectores como la juventud, que es fácilmente influenciable.

La tercera característica de la acción de los grupos irregulares en Colombia es su alta capacidad de adaptarse a los cambios que se presentan, logrando mutar de la acción armada a la combinación de todas las formas de lucha, de la utilización de la violencia al escenario político.

En un escenario en el cual la lucha revolucionaria violenta ha sido superada y proscrita en el mundo, los grupos que utilizaban dicha estrategia han tenido que reinventarse y buscar otros modos de lograr sus fines. Se puede evidenciar el aumento de las protestas sociales a nivel continental, las cuales buscan validar la llegada al poder de grupos de orientaciones no democráticas y que se basan en fundamentos ideológicos que han generado pobreza y atraso en los países donde se han implementado las orientaciones ideológicas del llamado Socialismo del Siglo XXI. 
La toma del poder, utilizando el caos que provoca la utilización violenta de la protesta social, es el objetivo de algunos grupos políticos, que, en coordinación con grupos irregulares, pretenden instaurar una dictadura democrática en varios países del continente. Para ello han tomado nuevamente elementos de la guerra política, para combinar todos los medios de lucha, hacer colapsar los sistemas políticos y finalmente tomar el poder.

El principal desafío del Estado colombiano frente a las características de este tipo de guerras es identificar los retos éticos que se generan en el desarrollo de las operaciones militares por intermedio de la gestión del conocimiento y, finalmente, diseñar estrategias que permitan superarlos, buscando la legitimidad como centro de gravedad en alcanzar el bienestar de la sociedad y la consecución de los intereses estatales.

\section{Dilemas éticos militares generados en las operaciones militares}

Se debe iniciar con comprender la importancia de la ética militar en el desarrollo de las operaciones, pues esta establece el marco de actuación de los individuos para el cumplimiento de su rol constitucional en un sistema democrático y liberal. Por lo tanto, los valores, principios y tradiciones militares, por lo menos en el caso colombiano, no son contrarios a los establecidos por la república ni por el sistema internacional, los cuales centralizan sus esfuerzos en garantizar las libertades naturales del ser humano y evitar cualquier amenaza o riesgo que atente contra la integridad física y mental del ser humano y de su entorno (territorio).

Para Moliner (2018a), la profesión militar tiene como objetivo preservar la paz, pero en escenarios de hostilidades puede ejercer la violencia letal y su mismo sacrificio con el fin de proteger la nación. Esta profesión goza de legitimidad y legalidad, ya que representa el monopolio del poder del Estado, el cual debe preservar el interés nacional, la soberanía y su integridad territorial.

Así las cosas, las instituciones militares tienen una función social importante, debido a que su esencia se soporta en una filosofía y el establecimiento de códigos de conducta morales considerados válidos y correctos (Moliner, 
2018b). Con ello, existe una distinción entre el ser militar y cualquier otra profesión, debido a que su formación profesional y humana se determina por valores y principios que son reforzados por la institución; esto implica el mantenimiento de tradiciones y pautas de conducta que se caracterizan de otro quehacer social. Por ello se entiende que

la ética es un saber para fundar y orientar racionalmente la acción humana hacia lo bueno, válido o correcto. Los seres humanos, queramos o no, tenemos una dimensión ética inherente a nuestra condición, la cual nos da una capacidad para inclinarnos hacia el bien o el mal en todos nuestros quehaceres vitales. También en el ejercicio de una profesión como la militar, la ética está indudablemente implicada y desempeña un papel primordial. (Moliner, 2018a, p. 11).

Según Moliner (2018a), son tres escenarios donde el militar debe emplear sus capacidades humanísticas, éticas y de liderazgo:

Ius ad bellum, relacionado con los principios referidos al uso de la fuerza, principio de causa justa y el principio de legítima defensa. En este se contemplan los requisitos para el inicio de una guerra justa, se trata de los elementos que se deben tener en cuenta antes del inicio de un conflicto y donde se reconocen conceptos como la autoridad, legitimidad, justicia y proporcionalidad. (Ruiz, 2004)

Ius in bellum, referido a la aplicación de principios como la discriminación y necesidad militar. Se relacionan con el desarrollo de operaciones militares y las prácticas que se deben aplicar durante la guerra, comprende también las reglas de guerra y el trato durante la guerra dirigido a los combatientes, métodos considerados, bienes lícitos y población civil. (Ruiz, 2004)

Ius post bellum, relacionado con los deberes y derechos que se deben aplicar con el vencido. Esto implica un apoyo hacia la construcción de paz. Este comprende el periodo relacionado con la fase final del conflicto. (Jaramillo \& Echeverry, 2005)

La profesión militar no solo implica el empleo de la fuerza, estrategias y tácticas, sino también consiste en la comprensión de los contextos sociales y políticos en el escenario antagónico. En este sentido, la ética militar es una competencia que establece el marco de actuación conforme a lo que es moralmente correcto, tanto en tiempos de guerra como en tiempos de paz, en razón 
a que los conflictos armados pueden externalizar los aspectos negativos del ser y sus pasiones antinaturales más profundas, desdibujar el límite del comportamiento humano determinado por el odio, el rencor, el revanchismo, la humillación, el dolor, entre otros sentimientos.

La ética, en un escenario del conflicto armado, es la que determina la esencia del individuo y si este sigue actuando conforme a un razonamiento moral o no, guiado por impulsos injustificados que desdibujan su esencia como ser humano. En consecuencia, se resalta que

otra manifestación de la exigencia de la ética militar es que proporciona al militar la capacidad de evaluar y ajustar los requisitos éticos de su profesión, sujetos a cambio acelerado y modificación profunda en muchas facetas de la misma, especialmente en las nuevas formas y medios de conflicto. (Moliner, 2018b, p. 31)

Es así que tanto la ética como la moral son los componentes esenciales en la vida militar para actuar sin extralimitación de las funciones, y de esta manera respetar la integridad del ser humano, resaltando, ante todo, que sin importar el contexto los combatientes son personas.

\section{Principios de la guerra: dilemas de la ética militar en las operaciones militares}

Existen principios en el derecho internacional que establecen los límites cuando se sostienen hostilidades en escenarios de conflicto armado internacional y no internacional. Estos tienen como objetivo establecer reglas de juego en el marco de una guerra, lo cual implica también la prohibición de métodos y medios para los enfrentamientos. Por otra parte, existen también principios propios de la necesidad militar que se tienen en cuenta en la planeación y la ejecución de las operaciones. Es aquí donde se presenta un dilema moral, entendido como las posibilidades de elegir entre dos o más opciones distintas que tienen consecuencias conflictivas y donde convergen principios y valores mutuamente incompatibles.

Por una parte, la legalidad entendida como la condición de que los comportamientos se ajusten a la ley y la norma (Mira, 2019). En este sentido, 
cualquier actuación que se encuentre conforme a la norma es lícita. No obstante, en el marco de conflictos asimétricos es muy difícil identificar a los antagonistas que participan en las hostilidades, debido a que los actores irregulares insurgentes no se acogen a principios normativos para el sostenimiento de las hostilidades, como el principio de distinción, de humanidad o de proporcionalidad y, en consecuencia, la mayoría de sus métodos y medios son ilícitos.

El dilema de las Fuerzas Armadas se pone a aprueba en las operaciones, pues los actores irregulares optan por todo tipo de métodos de guerra prohibidos, como perfidia, terror, represión, daños al medio ambiente, uso desproporcionado de la fuerza (Fuerza Aérea Colombia, 2020), y otros actos, como desaparición forzada, secuestro, detención arbitraria o toma de rehenes (Organización de las Naciones Unidas [ONU], 2003). Es aquí en donde se pone en juego la ética y el profesionalismo de los miembros de las Fuerzas para no incurrir en irregularidades al actuar de la misma manera que lo hacen los actores ilegales, y en contraposición, mantener la objetividad durante el transcurso de la operación.

Y por otra parte, la legitimidad entendida como el reconocimiento y cumplimiento en relación con la dimensión moral, normas y valores que rigen una comunidad o sociedad. Generalmente, este tipo de actuaciones o comportamientos no se enmarcan en un reglamento jurídico, sino que se trata de un criterio personal conforme a valores sociales comúnmente aceptados (Mira, 2019). Existen escenarios donde la legitimidad de un acto se confronta con la legalidad de una operación, y donde existe una línea muy delgada entre la moral y la ética.

Un ejemplo de lo anterior es el uso desproporcionado de la fuerza en las hostilidades. Por más que se cuente con la alta capacidad de fuego que puede tener un ejército legalmente constituido, el empleo de las armas y los métodos se deben ajustar al respeto de los Derechos Humanos, lo cual implica enfrentar casos donde el enemigo desconoce los principios y emplea métodos irregulares contra los miembros de la Fuerza Pública y contra la población civil. Por más grave que sea el delito, se tiene como principio el trato humanitario al enemigo combatiente y la proporcionalidad de la fuerza.

El dilema entre la legitimidad versus la legalidad se pone a prueba en el desarrollo de las hostilidades, más aún cuando el enemigo por su condición y 
naturaleza de irregular emplea métodos prohibidos a sabiendas de su actuación ilícita. Del mismo modo, las operaciones militares se plantean para generar el menor daño colateral posible, lo cual implica dejar pasar objetivos de alto valor si se tiene un índice de posibilidad alto de incurrir en la afectación de los derechos fundamentales de personas o el daño de bienes protegidos.

Uno de los marcos de regulación son los Convenios de Ginebra y sus Protocolos Adicionales. Conformados en 1949, los Convenios tenían como objetivo limitar la barbarie de la guerra mediante la construcción de normativas para la protección de civiles, personal médico y sanitario, las personas miembros de organizaciones humanitarias, así como también las personas que participan en las hostilidades, caso puntual, combatientes, heridos, enfermos y prisioneros de guerra. El fin último es impedir las infracciones contra los Derechos Humanos sin importar las personas de los bandos enfrentados (Comité Internacional de la Cruz Roja [CICR], 2014).

Por lo anterior, existen generalidades básicas que se deben tener en cuenta en el Derecho Internacional Humanitario: (1) principio de humanidad, relacionado con el trato digno a las personas que participen o no de las hostilidades; (2) principio de igualdad entre beligerantes, referente al respeto de los estatutos internacionales entre las partes enfrentadas; (3) principio de necesidad militar, referente al equilibrio entre las necesidades de la guerra y la normativa humanitaria; (4) principio de no discriminación, el cual recalca el trato igual sin ninguna distinción de raza, sexo, color o género; (5) principio del derecho de Ginebra, relacionado con el respeto de la normatividad internacional referente a las personas combatientes y civiles; (6) principio de inmunidad, el cual garantiza la existencia de personas civiles y bienes protegidos que no se deben contemplar en las hostilidades; (7) principio de prioridad humanitaria, referente al trato humanitario prioritario a las víctimas producto de conflicto armado; (8) principio de distinción, relacionado con la diferenciación entre combatientes y población civil; (9) principio de proporcionalidad, referente al uso proporcional de los métodos y las armas de guerra, y (10) principio de limitación de la acción hostil, el cual contempla el uso de armas y métodos de guerra que son permitidos.

Asimismo, en el quehacer militar, citando a De Izcue et al. (2013), existen principios para la solución de un problema estratégico que implica la revisión 
y el análisis de las enseñanzas producto de la guerra. Es así que el pensamiento estratégico y también el táctico establecen principios de la guerra:

Los principios de la guerra no deben constituir reglas rígidas que restrinjan la imaginación y la creatividad del conductor militar, sino que deben constituirse en orientaciones que faciliten y perfeccionen sus habilidades [...] son normas, guías o reglas generales, extraídas del estudio y análisis histórico de los conflictos armados, que proporcionan orientaciones que facilitan la solución de los problemas estratégicos y tácticos de la guerra, posibilitando alcanzar la victoria, de implementarse adecuadamente con base en la creatividad e ingenio militar. (De Izcue et al., 2013, pp. 23-25)

De este modo, se pueden identificar dos aspectos: el primero está relacionado con principios universales que deben ser respetados en un escenario de conflicto y, el segundo, los principios relacionados con la necesidad militar en escenario de conflicto, que son axiomas para el desarrollo de las operaciones, tales como la sorpresa, el engaño, la movilidad, la concentración, la iniciativa, la velocidad (De Izcue et al., 2013), entre otros, los cuales deben estar alineados con el respeto de los Derechos Humanos. En el caso de las Fuerzas Militares de Colombia, existe una formación permanente en favor del desarrollo del pensamiento crítico, el liderazgo y la competencia en cada uno de los niveles de la institución militar materializados en su doctrina humanista (Acosta, 2018).

En suma, por más lícitos que sean los métodos, todas las actuaciones deben estar alineadas al respeto de los derechos universales, más aún en el respeto de los principios del Derecho Internacional Humanitario. Es así que el ser militar no solo se relaciona con el uso proporcionado de la fuerza, sino también con el respeto de una serie de principios, valores, tradiciones y códigos de conducta que implican necesariamente el ejercicio de la ética en su actuar como profesional.

\section{Retos éticos de las Fuerzas Armadas frente a las nuevas amenazas}

Si bien el conflicto armado desarrollado entre el Estado colombiano y las FARC-Ep llegó a su fin con la firma del Acuerdo para la terminación del conflicto 
y la construcción de una paz estable y duradera, esto no significa que Colombia superara sus grandes desafíos en materia de seguridad. El posconflicto, de hecho, trae consigo nuevos escenarios y actores que amenazan la estabilidad del Estado y la sociedad colombiana y que, por su diversidad y multiplicidad, presentan un panorama de una gran complejidad, incluso, probablemente mayor que la del conflicto que acaba de finalizar. Asimismo, estas nuevas amenazas exceden el ámbito colombiano y se configuran como potenciales desestabilizadores a nivel global, por lo que adquieren una gran relevancia.

Esta categoría de nuevas amenazas, en lugar de referirse a un actor o grupo de actores en específico, remite a ciertas actividades delictivas que convergen entre sí y desestabilizan numerosos gobiernos y sociedades. De acuerdo con la Organización de Estados Americanos (OEA, 2003), esta categoría engloba diversas actividades, como el terrorismo, la delincuencia organizada transnacional, la corrupción, el lavado de activos, el tráfico de armas, la trata de personas o los ataques cibernéticos. En el caso colombiano específicamente, las nuevas amenazas constituyen diversas actividades, como delincuencia organizada, minería ilegal, narcotráfico, cibercrimen e, incluso, tráfico de migrantes (Cubides \& Ramírez, 2018).

Estas nuevas amenazas se refieren, entonces, a diversas actividades delictivas de distinta naturaleza que, sin embargo, tienen la capacidad de poner en riesgo la seguridad de sociedades enteras. Es decir, los Estados ya no perciben amenazas únicamente por parte de otros Estados o grupos insurgentes, sino que entran en escena una multiplicidad de actores de distinta índole, cuyas actividades, así no sea ese su propósito, desestabilizan al Estado y la sociedad. Por ello es fundamental el deber que tienen los gobiernos de combatir las nuevas amenazas desde el interior de sus Estados (Ardila \& Cubides, 2017). De igual manera, como estas amenazas tienen implicaciones globales, "los actores del sistema internacional tienen el deber de trabajar conjuntamente y de forma coordinada para contrarrestar los efectos de las nuevas amenazas" (Ardila \& Cubides, 2017, p. 33).

El deber del Estado de enfrentar los desafíos que amenazan la seguridad de sus ciudadanos nace desde el origen mismo de la comunidad política. El Estado está, primordialmente, para garantizar la seguridad de sus miembros. 
Sin embargo, el Estado no puede desarrollar su función de seguridad sin ningún limitante; es decir, no puede, en nombre de su seguridad, ejecutar cualquier acción o conducta que le conduzca a ella, sino que sus actividades deben cumplir con unos limitantes éticos que propenden al respeto de cualquier tipo de actor que podría verse perjudicado de manera injusta por la actividad estatal. Así, a través del tiempo se han configurado unos preceptos éticos reguladores de las actuaciones del Estado que se han denominado principios de la guerra.

Estos principios de la guerra se refieren a "los límites morales de la guerra en lo que respecta no a su legitimidad, sino al comportamiento de los individuos que participan en ella" (Lara, 2013, p. 80). Es decir, son preceptos éticos que regulan las acciones de los actores que forman parte de los conflictos armados, de manera que puedan cumplir con sus objetivos estratégicos causando el menor dańo y sufrimiento posible. Estos principios de la guerra se conocen también como ius in bello, es decir, el derecho en la guerra (Salim, 2015).

En la sección anterior se explicaron en detalle estos principios reguladores del uso de la fuerza por parte del Estado. Así, se trataron principios como el de humanidad, el de igualdad entre los beligerantes, el de necesidad militar, el de distinción, el de prioridad humanitaria, entre otros. Tales preceptos, como se ha sostenido, apuntan a la limitación de las actividades del Estado, o mejor, de sus funcionarios, en materia de seguridad, de manera que cumplan con los fines estatales ocasionando el menor perjuicio posible. Es decir, estos principios de la guerra son deberes éticos de la conducta estatal en el uso de la fuerza.

Durante las últimas décadas, estos principios éticos del uso de la fuerza se han materializado en lo que se conoce como Derecho Internacional Humanitario (Diн). Esta categoría jurídica, también conocida como el "derecho de la guerra", engloba todas las normas internacionales elaboradas para la regulación de los conflictos armados (Ramírez, 2009). De estas, las más conocidas son los Convenios de Ginebra con sus Protocolos Adicionales. Sin embargo, dicha categoría comprende toda norma, sea escrita o consuetudinaria, tendiente a limitar los efectos de los conflictos armados (CicR, 2004).

De igual manera, un eje fundamental del DiH es la distinción entre combatiente y no combatiente. Por medio del Derecho Internacional Humanitario 
se trató de erradicar los daños en contra de los civiles, pues al no ser partícipes de las hostilidades, no tiene sentido que sean las personas más afectadas en las confrontaciones armadas. Por ello, el DiH

protege a las personas que no toman parte en las hostilidades, como son los civiles y el personal médico y religioso. Protege asimismo a las personas que ya no participan en los combates, por ejemplo, los combatientes heridos o enfermos, los náufragos y los prisioneros de guerra. Esas personas tienen derecho a que se respete su vida y su integridad física y moral, y se beneficien de garantías judiciales. (CICR, 2004, p. 2)

Así, del DiH se extraen algunos compromisos éticos que adquieren los actores parte de los conflictos armados, como el respeto por los civiles y los combatientes. Más allá de cada disposición sustantiva, el espíritu del DiH es materializar las obligaciones éticas y morales que tienen los Estados y, por consiguiente, sus funcionarios, y que van más allá de la distinción entre combatiente y no combatiente, para abordar cada uno de los principios del uso de la fuerza que han sido mencionados con anterioridad.

Sin embargo, dada la naturaleza de las nuevas amenazas, el DiH se queda corto como instrumento jurídico garante de estos principios éticos del uso de la fuerza. Como se pudo observar, las nuevas amenazas abordan distintas modalidades de criminalidad que exceden el ámbito de los conflictos armados, y que pueden responder a distintas finalidades de diversos órdenes, como el puramente lucrativo. De esta manera, al ser el DiH un instrumento regulador de los conflictos armados específicamente, es inaplicable en el enfrentamiento de las nuevas amenazas en su conjunto.

No obstante, los principios del uso de la fuerza, como imperativos éticos, son inmutables (Jiménez et al., 2019). Por ello, no se restringen a los escenarios de los conflictos armados, sino que enmarcan toda situación en la que el Estado haga uso de la fuerza. Por consiguiente, el cumplimiento de estos principios del uso de la fuerza en los escenarios de enfrentamiento de estas nuevas amenazas constituye un verdadero reto ético para el Estado y, con él, para sus Fuerzas Armadas.

En este sentido, la respuesta del Estado a los desafíos éticos que suponen la proliferación de estas nuevas amenazas se materializa en la construcción 
de una categoría jurídica que aborde estos principios en escenarios operacionales más allá de la existencia o no de un conflicto armado. Así se da origen al Derecho Operacional (Doper), como un esfuerzo por cumplir con tales preceptos éticos en todo tipo de operaciones de las Fuerzas Armadas.

En Colombia, las Fuerzas Armadas entienden por Derecho Operacional "la integración de los tratados internacionales ratificados por Colombia, la legislación nacional y la jurisprudencia en materia de Derechos Humanos y Derecho Internacional Humanitario al planeamiento, ejecución y seguimiento de las operaciones, operativos y procedimientos de la Fuerza Pública” (Comando General de las Fuerzas Militares, 2015, p. 13). Sin embargo, el Doper va más allá de las normas de Derechos Humanos y de Derecho Internacional Humanitario, pues, según Mejía et al. (2019), el Derecho Operacional también está compuesto por normas de otras materias, como el derecho constitucional, el derecho penal, el derecho administrativo o el derecho civil, aplicables en el marco de las operaciones militares. Por consiguiente, el Derecho Operacional es una categoría que engloba todas las normas jurídicas que regulen "la conducción de hostilidades y otras misiones militares en tiempos de guerra, transición, estabilización o paz, en cuanto al uso de la fuerza" (Comando General de las Fuerzas Militares, 2015, p. 13).

El Doper es fundamental para el cumplimiento de las funciones de las Fuerzas Armadas y de Policía en la actualidad. Esto se presenta en la medida en que es ese referente normativo que, entre otros aspectos, estudia y limita el uso de la fuerza, regula los medios en la conducción de las hostilidades, establece las reglas de enfrentamiento y define los objetivos militares y cómo se enfrentan (Comando General de las Fuerzas Militares, 2015). Asimismo, estas normas jurídicas regulan con gran especialidad los ámbitos operacionales, ya que no solo establecen y desarrollan los principios del uso de la fuerza, sino que además contienen disposiciones de carácter tan específico como la creación de la figura del asesor jurídico operacional o cómo se debe proceder en una captura y después de esta. Es decir, el Doper no se limita a enunciar la obligatoriedad de los principios del uso de la fuerza o a plasmarlos en normas generales, sino que comprende normas de carácter muy específico en las que estos preceptos éticos pueden desempeñar la función de causa primera. 
En síntesis, el Derecho Operacional, toda su estructura y sus disposiciones de carácter más específico, tiene como objeto de estudio el uso de la fuerza y la conducción de las hostilidades (Chíquiza \& Gil, 2019). El Doper cubre todos los escenarios en los que el Derecho Internacional Humanitario es inaplicable, pues este último se reduce al ámbito de los conflictos armados, mientras que el Doper puede abarcar tanto estos escenarios como aquellos que están fuera de esa esfera, es decir, aquellos contextos de paz o de transición. De igual manera, el Doper está fundamentado en el mismo espíritu del Dir, a saber, el cumplimiento de los principios del uso de la fuerza, pues estos preceptos éticos son inmutables, es decir, son permanentes a pesar de las transformaciones de los escenarios en los que dicha fuerza es utilizada.

Así, las nuevas amenazas no suponen nuevos retos éticos para las Fuerzas Armadas. Si bien en el paradigma tradicional de los conflictos armados, el enemigo, es decir, el grupo armado al que se enfrente, tiene la obligación de cumplir con las normas del Derecho Internacional Humanitario, las nuevas amenazas no están sujetas a ningún ordenamiento regulador de sus actividades en la medida en que su naturaleza es eminentemente criminal. No obstante, las Fuerzas Armadas deben seguir los principios del uso de la fuerza así su contraparte no respete ningún ordenamiento jurídico o moral. En ese sentido, sea un grupo armado o una organización de crimen transnacional, el Estado siempre deberá seguir los principios del uso de la fuerza a la hora de combatirlos. Por lo tanto, los retos éticos a los que se enfrentan las Fuerzas Armadas en el marco de las nuevas amenazas son los mismos que tradicionalmente han enfrentado en la antigua dinámica de los conflictos armados: lograr los objetivos militares cumpliendo con los principios reguladores del uso de la fuerza. Lo que cambia es el contexto.

\section{Conclusión}

Se reconoce la existencia de los dilemas éticos, que, entre otras cosas, forman parte del quehacer militar y son retos permanentes para los miembros de las Fuerzas Armadas. Esto implica que la formación del militar se ve abocada a fortalecer las competencias éticas, morales y de liderazgo conforme 
a los códigos de conducta establecidos en la institución. Por lo tanto, el ser militar no solo implica el ejercicio y uso del monopolio de las armas, sino que también se trata de una noble profesión que implica el respeto del ser y la garantía de los derechos y deberes que implica ser humano.

En el marco de los retos de las Fuerzas Militares ante las nuevas amenazas, el Doper, como constructo jurídico, ofrece una solución. Las nuevas amenazas, por su naturaleza, han hecho que el Derecho Internacional Humanitario se quede corto y no logre abarcar los deberes de las Fuerzas del Estado en esas nuevas dinámicas externas a los conflictos armados. En ese sentido, el Derecho Operacional constituye la adaptación de esos principios éticos del uso de la fuerza a los novedosos escenarios propios de las nuevas amenazas. De esta manera, el Derecho Operacional se fundamenta en los retos éticos de las Fuerzas Armadas frente a las nuevas amenazas, que son los mismos que ha asumido el Estado desde que estableció un límite al uso de la fuerza para garantizar su seguridad, solo que se enfrentan a escenarios totalmente nuevos y desconocidos.

\section{Referencias}

Acosta, H. (2018). Impacto de la Doctrina Damasco sobre los procesos de educación militar:

El liderazgo militar en escenario de Pos-acuerdo. En C. Ardila \& J. Jiménez (eds.), Convergencia de conceptos: propuesta de solución a las amenazas actuales para la seguridad y defensa de Colombia (pp. 91-130). Escuela Superior de Guerra.

Ardila, C., \& Cubides, J. (2017). Política pública de seguridad en Colombia frente a la convergencia y las nuevas amenazas. En C. Ardila \& V. Torrijos (eds.), Politicas públicas de seguridad y defensa: Herramientas en el marco del postconflicto en Colombia (pp. 22-56). Escuela Superior de Guerra.

Boot, M. (2013). Invisible armies, an epic history or guerrilla warfare, from ancient times to the present. Liveright Publishing Corporation.

Centro Nacional de Memoria Histórica. (2014). Guerrilla y población civil. La trayectoria de las FARC, 1949-2013 [Informe del Centro Nacional de Memoria Histórica]. Imprenta Nacional. http://www.centrodememoriahistorica.gov.co/descargas/informes2013/farc/ guerrilla-poblacion-civil.pdf

Chíquiza Gómez, F. A., \& Gil Osorio, J. F. (2019). El derecho operacional como una categoría dentro de la taxonomía del derecho. Vniversitas, 68(139). https://doi.org/10.11144/ Javeriana.vj139.doct. 
Comando General de las Fuerzas Militares. (2015). Manual de Derecho Operacional para las Fuerzas Militares. Imprenta y Publicaciones de las Fuerzas Militares.

Comité Internacional de la Cruz Roja [CICR]. (2004) ¿Qué es el Derecho Internacional Humanitario? https://www.icrc.org/es/download/file/3648/dih.es_.pdf

Comité Internacional de la Cruz Roja [CICR]. (2014). Los Convenios de Ginebra de 1949 y sus protocolos adicionales. https://www.icrc.org/es/document/los-convenios-de-ginebra-de-1949-y-sus-protocolos-adicionales

Cubides, J., \& Ramírez, E. (2018). Una mirada a la construcción de paz desde la seguridad humana en Colombia en el escenario de posconflicto. En C. Ardila \& J. Jiménez (eds.), Convergencia de conceptos: Enfoques sinérgicos en relación a las amenazas a la seguridad del Estado colombiano (pp. 141-172). Escuela Superior de Guerra.

De Izcue Arnillas, C., Arriarán, A., \& Tolmos, Y. (2013). Apuntes de la estrategia operacional. http:// virtual.esup.edu.pe/bitstream/ESUP/157/1/Apuntes\%20de\%20Estrat\%C3\%A9gia\%20 Operacional\%20.\%20pdf

Fuerza Aérea Colombia. (2020). Métodos de guerra. https://www.fac.mil.co/m\%C3\%A9todos-de-guerra\#:-:text=Entre\%20los\%20m\%C3\%A9todos\%20de\%20guerra,obras\%20 e\%20instalaciones $\% 20$ que $\% 20$ contienen

Gil J., Jiménez J., \& Acosta. H. (2019). Categorización de los Grupos Armados Organizados (GAO) en el Derecho Internacional Humanitario. En C. Espaliú (ed.), El conflicto y su situación actual: Del terrorismo a la amenaza hibrida (pp. 219-234). Thomson Reuters.

Guevara, E. (2006). La guerra de guerrillas. Ocean Sur.

Jaramillo J., \& Echeverry, Y. (2005). Las teorías de la guerra justa. Implicaciones y limitaciones. Revista Cientifica Guillermo de Ockham, 3(2), 9-29.

Jiménez, J., \& Acosta, H. (2018). La geopolítica criminal de los grupos armados organizados. En C. Ardila \& J. Jiménez, Convergencia de conceptos: Enfoques sinérgicos en relación a las amenazas a la seguridad del Estado colombiano (pp. 85-115). Escuela Superior de Guerra.

Jiménez J., Acosta. H., \& Díaz, W. (2019). Importancia del fortalecimiento de la estructura de valores en las Fuerzas Militares. En C. Giner (ed.), Los nuevos escenarios en las relaciones internacionales: Retos, amenazas y oportunidades (pp. 95-108). Thomson Reuters.

Kalyvas, N. (2009). El carácter cambiante de las guerras civiles 1800-2009. Colombia Internacional, (70), 193-214.

Lara, F. (2013). Ética en la guerra: La distinción entre soldados y civiles. Revista de Filosofía, 38(2), 79-98. https://doi.org/10.5209/rev_RESF.2013.v38.n2.43389.

Mark, T. (2006). Regain the initiative: Colombia versus FARC insurgency. En D. Marston \& C. Malaysian, Counterinsurgency in modern warfare (pp. 162-181). Osprey Publishing.

Medina, M. (2013). FARC-EP, flujos y reflujos, la guerra en las regiones. Universidad Nacional de Colombia.

Mejía, J., Caldera, J., \& Jiménez, J. (2019). Retrato del derecho operacional en Colombia desde la academia. Revista de Ciencias Humanas y Sociales, (25), 975-1014.

Mira, H. (2019, junio 1). Legal y moral, legalidad y legitimidad. https://www.elmundo.com/ noticia/Legal-y-morallegalidad-y-legitimidad/376732 
Moliner, J. (2018a). ¿Qué es la ética militar? http://www.ieee.es/Galerias/fichero/docs_ marco/2018/DIEEEM16-2018_EticaMilitar_JAMoliner.pdf

Moliner, J. (2018b). ¿Por qué es importante la ética militar? Revista Española de Defensa, 30-21. https://www.defensa.gob.es/Galerias/gabinete/red/2018/red-353-etica-militar.pdf

Organización de las Naciones Unidad [ONU]. (2003). Los Derechos Humanos, el Derecho Internacional Humanitario, el secuestro y los acuerdos especiales. https://www.hchr.org. co/publico/pronunciamientos/ponencias/po0319.pdf

Organización de los Estados Americanos [OEA]. (2003). Conferencia especial sobre seguridad. Declaración sobre seguridad en las Américas. http://www.oas.org/36AG/espanol/doc_ referencia/DeclaracionMexico_Seguridad.pdf

Ramírez, A. (2009). Diferencias teórico-prácticas entre Derechos Humanos y Derecho Internacional Humanitario. Via Iuris, (8), 93-122.

Ruiz, A. (2004). Guerra, justicia y Derecho Internacional. Isonomía. Revista de Teoría y Filosofía del Derecho, (20), 59-72.

Salim, B. (2015). La aplicación del uso de la fuerza en el ius ad bellum y el ius in bello. Derecho y Cambio Social, 12(40), 25.

Sarmiento E., J. (2017). Aproximaciones a algunos desafíos de la implementación del Acuerdo de La Habana en el Caribe colombiano. Revista de Derecho, (48), 7-11.

Sheng, W. (1974). Teoría y práctica de la guerra política. Escuela de Guerra Política.

Trejos, L.(2013). Aproximaciones a la actividad internacional de una organización insurgente colombiana. El Ejército Popular de Liberación (EPL). De China a Cuba vía Albania. Investigación \& Desarrollo, 21(2), 371-394.

Wu, S. (1992). El arte de la Guerra del maestro Sun Tzu. Elektra. 